\title{
Por uma Nova Abordagem de Mudança Social: A Comunicação do Compromisso ${ }^{1}$
}

\author{
Robert Vincent Joule ${ }^{2}$ \\ Françoise Bernard \\ Université de Provence
}

\begin{abstract}
RESUMO - Os limites das ações de comunicação que repousam sobre a informação e a persuasão são conhecidos. Se elas permitem modificar as atitudes e os saberes, elas não permitem, entretanto, modificar os comportamentos efetivos, porque boas atitudes não são suficientes para ter bons comportamentos. O objetivo deste artigo é propor uma nova abordagem de mudança social à luz da teoria do compromisso. Três estudos são relatados, mostrando sua eficácia para promover os comportamentos de cidadania desejados (participação eleitoral, proteção do meio-ambiente e economia de energia). Esta abordagem, chamada "comunicação do compromisso", apóia-se sobre os atos preparatórios e os atos de comprometimento que convém obter das pessoas enfocadas.
\end{abstract}

Palavras-chave: mudança social; comunicação; cidadania; compromisso; decisão.

\section{For a New Approach of Social Change: Committing Communication}

\begin{abstract}
We already know the limits of communication actions based on information and persuasion. If that type of actions can lead to changing attitudes and knowledge, they hardly allow modifying the effective behaviours, simply because having the right attitudes is usually not enough to have the right behaviour. The goal of this article is to propose a new approach of social change in the light of the commitment theory. Three studies are reported, which show this theory efficiency to promote required citizenship behaviours: electoral participation, environmental protection and saving energy. This approach, called "committing communication", is based on preparatory acts and acts of commitment which are necessary to obtain from target subjects.
\end{abstract}

Key words: social change; communication; citizenship; commitment; decision.

Votar, respeitar o código de trânsito, doar sangue, controlar o consumo de energia, bem como intervir para evitar que um roubo seja cometido, socorrer uma pessoa em perigo no metrô, todos estes atos pertencem à categoria de comportamentos de "cidadania" bastante valorizados. Ouve-se falar, quase todo dia, que a promoção destes comportamentos passa por uma mudança de mentalidades e que é preciso, antes de tudo, melhor informar, melhor convencer, enfim, torná-los objetos de uma ação pedagógica. Tem-se, também, apresentado à rádio, à televisão, bem como à escola, à família ou a outras instâncias sociais, as virtudes da informação e da persuasão para levar crianças e adultos a adotar idéias e valores necessários ao funcionamento da sociedade. Se assim se procede é porque se supõe que esta modificação de idéias ou de valores vai ser acompanhada por uma modificação efetiva dos comportamentos. A maioria das grandes campanhas de comunicação, bem como as lições de moral ou de instrução cívica assentam-se sobre este pressuposto.

Infelizmente, não é suficiente ter "boas idéias" para se ter "bons comportamentos". Um cuidadoso estudo longitudinal,

1 Texto traduzido pela Profa. Angela Maria de Oliveira Almeida, coordenadora do Laboratório de Psicologia Escolar, Instituto de Psicologia, Universidade de Brasília.

2 Endereço: Université de Provence, Laboratoire de Psychologie Sociale, 29 avenue R. Schuman, Aix-en-Provence Cédex 1, 13621 France. E-mail: joule-rv@up.univ-aix.fr realizado há alguns anos nos Estados Unidos (Peterson, Kealey, Mann, Marek \& Sarason, 2000), mostrou que a probabilidade de ser um fumante aos 17 anos não é menor entre os alunos que freqüentaram pelo menos 65 sessões de "sensibilização" entre oito e 17 anos (condição experimental) - e, portanto, perfeitamente informados dos prejuízos do tabaco - que nos alunos que não seguiram estas sessões (condição controle). E este estudo - os psicólogos sociais o sabiam (notadamente Wicker, 1969, e mais recentemente Baluch, Randhawa, Holmes \& Duffy, 2001) - é apenas um entre muitas outras pesquisas que ilustram a distância que pode existir entre nossas idéias - no caso, nossas "boas idéias" - e nossos atos. Evidentemente, isto não significa que informar não serve para nada ou que argumentar não serve para nada. A informação e a argumentação servem, incontestavelmente, ao longo do tempo, para modificar os saberes, as idéias, as atitudes e até mesmo provocar reais tomadas de consciência. A informação e a argumentação são, portanto, necessárias; necessárias sim, mas não suficientes. Um bom exemplo: pode-se perfeitamente estar convencido da necessidade de doar sangue e jamais fazê-lo. Temos, portanto, "boas idéias" em nossas cabeças. Sabemos que a doação de sangue não representa risco algum para a nossa própria saúde. Sabemos, sobretudo, que ela pode salvar vidas. Até mesmo conhecemos pessoas, entre nossos amigos ou próximos, que um dia precisaram receber sangue. Se não doamos nosso sangue, apesar das inúmeras ocasiões que se apresentaram diante de 
nós, não é porque nossas idéias nos ditam para não fazê-lo. Muito pelo contrário. Aliás, sentimos que bastaria "pouca coisa" para que realizássemos este ato cidadão.

\section{A submissão livremente consentida}

Há pelo menos 60 anos, os psicólogos sociais fizeram deste "pouca coisa" um apaixonante objeto de estudo, de tal forma que dispomos hoje de um denso saber científico, sobre o qual podem se apoiar aqueles que queiram favorecer a passagem ao ato cidadão. Propusemos (Joule \& Beauvois, 1998) agrupar os numerosos trabalhos sobre este objeto de estudo em um grande paradigma de base: a submissão livremente consentida. Este paradigma pode ser definido a partir de:

- um ponto de vista prático, como o estudo dos procedimentos suscetíveis de levar o outro a modificar livremente seus comportamentos (Joule \& Beauvois, 2002) e

- um ponto de vista teórico, como o estudo dos efeitos cognitivos e comportamentais que tais procedimentos são suscetíveis de engendrar (Joule, 1999).

Os primeiros trabalhos que este paradigma reúne remontam aos anos 1940 e às célebres pesquisas-ação realizadas por Kurt Lewin. Lembramos a fraca eficácia das estratégias persuasivas testadas por Lewin (1947), durante a Segunda Guerra Mundial, para incitar as donas de casa americanas a modificar seus hábitos alimentares. Para prevenir os problemas da má nutrição, era preciso que cozinhassem pedaços de carne considerados menos "nobres" (coração, tripas, etc.). Voltando para suas casas, após a conferência, elas estavam perfeitamente convencidas pelos argumentos que puderam ouvir. Suas novas convicções não as impediram, entretanto, de se comportar exatamente como se não tivessem assistido à conferência. Lembramos, também, que Lewin não se curvou diante deste fracasso. Uma nova estratégia foi testada. A principal diferença se deve a pouca coisa, esta "pouco coisa" de que falamos anteriormente: desta vez, a pessoa que fazia as intervenções na conferência tinha como instrução incitar as donas de casa, no final da reunião, a tomar publicamente a decisão de cozinhar, usando tais cortes de carne nos próximos dias. Assim, elas foram convidadas a levantar a mão para testemunhar sua decisão. Este simples gesto (levantar a mão) foi determinante, já que $32 \%$ dentre elas serviram, efetivamente, os pedaços menos nobres. Dez vezes mais que com a estratégia precedente.

Se as mudanças de idéia não desembocaram diretamente sobre mudanças de comportamentos, pode ser suficiente um "quase nada" para conduzir a mudanças comportamentais tão difíceis de obter, como aquelas que concernem o registro de hábitos alimentares familiares. Lewin (1951) explicará esta diferença argumentando que a relação entre idéia e comportamento não é direta. É necessário, por conseqüência, fazer intervir um elo intermediário e este elo intermediário não é outro, para Lewin, que o ato de decisão. Em outras palavras, tendo decidido, estamos, de uma forma ou de outra, ligados a nossa decisão. É este elo que traduz a noção de "efeito gelo", tão cara a Lewin. A decisão de se comportar, de tal ou tal maneira, uma vez tendo sido tomada, vai, de certa forma, congelar o universo de opções possíveis e conduzir a pessoa que decide a permanecer sobre esta sua decisão particular. É esta a razão pela qual as decisões que tomamos, ou que nos levam a tomar, nos comprometem.

Esta primeira pesquisa mostra o quanto é interessante obter decisões daqueles cidadãos, cujos hábitos se deseja mudar. E estas decisões, a priori banais, podem ir longe. Moriaty (1975) mostrou que elas podem facilmente transformar um espectador em ator. Sabemos que é muito pequena a probabilidade de uma testemunha intervir espontaneamente para impedir que um ladrão pegue alguma coisa de alguém. Entretanto, é preciso pouca coisa para que todo mundo, ou quase, intervenha: é preciso que a vítima tenha previamente pedido aos sujeitos para vigiar suas coisas em sua ausência. Neste caso, $95 \%$ (em uma praia) e $100 \%$ (em um restaurante) das testemunhas se interpuseram ao ladrão para impedi-lo de roubar. Se eles se interpuseram para impedir um roubo, realizando assim o ato cidadão desejado, não foi porque estes sujeitos têm idéias ou valores diferentes daqueles que não se interpuseram. Foi simplesmente porque, contrariamente aos outros, tinham assumido o "compromisso" de fazê-lo.

Nas duas pesquisas acima pontuadas, o processo psicológico que conduz à mudança de comportamento repousa sobre uma decisão (decisão de usar os pedaços de carne menos nobres, decisão de vigiar as coisas de alguém) e sobre o "efeito gelo" que daí resulta. Não é preciso dizer que certas decisões são mais difíceis que outras para se obter e devem, portanto (e por isso), ser objeto de uma preparação. As técnicas, que permitem preparar as decisões suscetíveis de conduzir as pessoas a realizarem livremente os comportamentos que se espera, são numerosas (Joule \& Beauvois, 2002). Evocaremos aqui, contudo, apenas uma dentre elas, a mais conhecida: o "dar-oprimeiro-passo"3 (Burger, 1999; Freedman \& Fraser, 1966). Ela consiste em preparar a decisão relativa ao comportamento desejado através da realização prévia de um comportamento muito menos difícil de obter (ato preparatório); enfim, obter um pouco, antes de pedir muito.

\section{A técnica de "dar-o-primeiro-passo"}

Em uma das primeiras pesquisas visando provar a eficácia da técnica do "dar-o-primeiro-passo", os pesquisadores tinham por objetivo levar as pessoas a aceitarem a colocação de um grande out-door em seu jardim, pedindo prudência aos motoristas (comportamento esperado). Este ato cidadão não é fácil de se obter. Formulando diretamente esta solicitação ( situação controle), eles obtiveram uma taxa de aceitação de apenas $17 \%$. Ao recorrerem à técnica do "dar-o-primeiropasso", obtiveram uma taxa de aceitação de 76\%. O ganho foi, portanto, apreciável. Desta vez, ao invés de formularem diretamente o pedido relativo à colocação do out-door, os pesquisadores começaram por um pedido infinitamente menos custoso e suscetível de ser aceito por praticamente todo mundo: colocar na beirada de sua janela um adesivo minúsculo, de $4 \mathrm{~cm}$ x $5 \mathrm{~cm}$, sobre o tema da prudência no volante.

Se em uma dada situação, o número de pessoas que aceita realizar o ato cidadão desejado é maior do que em uma outra, não é porque suas idéias, ou seus valores, são diferentes. Mais uma vez, o que distingue aquelas que aceitam maciçamente

3 Nota da tradutora: em francês "pied-dans-la-porte". 
daquelas que recusam maciçamente é pouca coisa: terem ou não sido levadas pelas "circunstâncias" a colocar um pequeno adesivo em sua janela.

Tudo se passa como se a realização de um pequeno ato em favor de uma causa (aqui a segurança no trânsito) levasse a outros, predispondo, assim, as pessoas que deram um primeiro passo a irem em frente, na mesma direção.

Na pesquisa do "dar-o-primeiro-passo" que acaba de ser evocada, o comportamento esperado foi objeto de uma demanda explicita: "Você aceitaria colocar um out-door no seu jardim?". Este não é o caso de outras pesquisas, nas quais se se contenta em criar condições susceptíveis de levar a pessoa a fazer espontaneamente o que se espera dela. Este é o caso notadamente de uma pesquisa que nós realizamos em Aix-enProvence (Joule \& Beauvois, 2004). Em uma ruazinha deserta, um pedestre perde uma nota de dinheiro. Apenas $20 \%$ das testemunhas lhe avisam. As outras deixam que ele se afaste, antes de pegar o dinheiro. Foi preciso, no entanto, apenas um ato preparatório bem escolhido para aumentar a probabilidade de ver as testemunhas se comportarem honestamente. Esta probabilidade é de $40 \%$ (portanto, o dobro) quando este ato preparatório consiste em fazer, anteriormente, um pequeno favor (dar uma informação) para um outro pedestre. Ela é de 70\% (mais que o triplo) quando o favor solicitado é sensivelmente mais custoso (andar uns 30 metros a fim de ajudar alguém a encontrar seu caminho). Novamente, se certos habitantes de Aix-en-Provence se mostram mais honestos que outros, não é porque suas idéias ou valores sejam diferentes, mas sim porque eles foram conduzidos, em um primeiro momento, a realizar um certo ato preparatório (fazer um favor praticamente banal). Tudo se passa como se o primeiro favor permitisse àquele que o fez estabelecer um elo entre o que ele fez (no caso, dar uma informação ou dar alguns passos para ajudar uma pessoa a encontrar seu caminho) e o que ele é (alguém prestativo e, de forma mais geral, uma boa pessoa). E uma boa pessoa não alertaria um pedestre que perde um dinheiro sob seus olhos?

\section{A Psicologia do Compromisso ${ }^{4}$}

É na psicologia do compromisso (Joule \& Beauvois, 1998; Kiesler, 1971) que convém buscar os fundamentos teóricos sobre os quais repousam os principais procedimentos de submissão livremente consentida.

\section{Definições de compromisso}

A primeira definição desta idéia de compromisso data da metade dos anos 1960. Devemo-la à Kiesler e Sakumura (1966): "o compromisso é o elo que une o indivíduo a seus atos comportamentais" (p. 349). Esta definição coloca os atos em primeiro plano. Não são nossas idéias, nossas convicções ou nossas crenças que nos levam a assumir compromissos, mas nossos atos enquanto tais. Se esta definição tem o mérito de dar um status particular aos atos, ela não é, entretanto, inteiramente satisfatória. Não é, porque mantém uma confusão entre o compromisso e a conseqüência do compromisso. É precisamente porque há compromisso que um laço vai poder se estabelecer entre o indivíduo e seus atos.

4 Nota da tradutora: em francês "psychologie de l'engagement".
E este compromisso depende da situação, já que é ela - em função de suas características objetivas - que compromete ou não compromete o individuo em seus atos e aqui, pela via da conseqüência, favorece, ou ao contrário entrava, ou até mesmo proíbe, o estabelecimento de um laço entre ele e seus comportamentos. Ora, a definição proposta por Kiesler e Sakumura negligencia a situação na qual o ato é realizado. Assim, preferimos, de nossa parte, definir o compromisso como: "o compromisso corresponde, em uma dada situação, às condições nas quais a realização de um ato só pode ser imputada àquele que a realizou" (Joule \& Beauvois, 1998, p. 60).

Pode-se, portanto, intervir sobre as condições nas quais o ato é realizado e, produzir um compromisso mais ou menos forte. Pode-se, notadamente, intervir sobre:

- O contexto de liberdade no qual o ato é realizado: um ato realizado em um contexto de liberdade vai implicar em um maior compromisso do que um ato realizado em um contexto de pressão.

- O caráter público do ato: um ato realizado publicamente vai implicar em um maior compromisso do que um ato cujo anonimato é garantido.

- A repetição de um ato: um ato que se repete vai implicar em um maior compromisso do que um ato realizado uma única vez.

- As consequiências do ato: um ato vai implicar em um maior compromisso quanto mais sérias forem as conseqüências.

- O custo do ato: um ato vai implicar em um maior compromisso, quanto mais ele é custoso (em dinheiro, em tempo, em energia, etc).

- As razões do ato: um ato vai implicar em um maior compromisso, tanto mais possa ser imputado a razões externas (por exemplo: promessas de recompensas, ameaças de punição) e que possa ser imputado a razões internas (por exemplo: valores pessoais, traços de personalidade).

\section{Da comunicação clássica à comunicação do compromisso}

Nossa prática de pesquisador mostrou-nos o interesse de inserir as campanhas de comunicação em uma dinâmica do compromisso (Joule \& Beauvois, 1998, 2000). O "dar-oprimeiro-passo", por exemplo, mostra-nos que existem mais chances de ser ouvido quando os argumentos mostrados (ou as informações dadas) são precedidos pela obtenção de um comportamento preparatório; mas não qualquer um: deve ser um comportamento consistente - no sentido das teorias da consistência cognitiva (Feldman, 1966) - com os argumentos (ou as informações) veiculados pela mensagem persuasiva. Não é a mesma coisa ser diretamente confrontado a uma demanda, por melhor argumentada que ela seja, e de ser confrontado com a mesma demanda após ter emitido um ato consistente com ela, sobretudo se este ato foi obtido em um contexto em que se assumiu um compromisso, isto é, em condições tais que não podemos explicar o que fizemos a não ser através de fatores internos (nossos gostos, nossas convicções, nossas atitudes pessoais), à exclusão de todos os fatores externos (pressões situacionais, promessas de recompensa ou ameaças de punição, etc). 
Foram estas considerações que nos conduziram a conceber um novo procedimento de comunicação, que denominamos "comunicação do compromisso", procedimento que se diferencia dos procedimentos clássicos pelos atos preparatórios que convém obter da parte dos receptores. A título de exemplo, evocaremos três ações de comunicação do compromisso que realizamos recentemente. A primeira visa a luta contra o absenteísmo eleitoral, as duas outras visam promover a eco-cidadania.

\section{Lutar contra o absenteísmo eleitoral}

Esta pesquisa (Deschamps, Joule \& Gumy, 2005) foi realizada na Suíça. Duas formas de proceder foram testadas junto aos estudantes, alguns dias antes de um escrutínio referente aos acordos bilaterais entre a Suíça e a União Européia. A primeira forma de proceder assenta-se na comunicação clássica, a segunda na comunicação do compromisso.

Em um grupo de estudantes (condição de comunicação clássica), o experimentador se contentava em fazer um discurso contra o absenteísmo eleitoral. Ele dava notadamente as informações sobre a preocupante baixa na participação nas eleições na Suíça e insistia sobre a necessidade de mobilizar o eleitorado. Em um outro grupo (condição de comunicação do compromisso), o experimentador tinha o mesmo discurso, mas ele se esforçava, ainda, para obter da parte dos estudantes um ato preparatório. Este ato consistia em responder por escrito às duas seguintes questões:

1. No seu ponto de vista, quais aspectos deveriam prioritariamente ser mudados para conseguir aumentar a participação nos escrutínios?

2. Imagine os argumentos que você poderia dar a um "absenteísta convicto" para encorajá-lo a ir votar.

Nas condições de comunicação clássica, $42 \%$ dos estudantes compareceram efetivamente às urnas. Este número se eleva a $83 \%$ na condição de comunicação do compromisso. Deve-se salientar que, tal como na pesquisa de Lewin (1947), as medidas de intenções comportamentais, efetuadas ao término da intervenção, não permitem anunciar a menor diferença entre as duas condições: os estudantes se declararam prontos para ir votar em proporções extremamente elevadas nos dois casos (respectivamente $84 \%$ e $88 \%$ ). Acontece que alguns o fazem enquanto outros não o fazem, o que ilustra novamente a distância que pode existir entre as boas idéias - e mesmo as boas intenções - e os atos, e ilustra também que é preciso pouca coisa.

\section{Promover a eco-cidadania nas escolas}

A primeira pesquisa (Joule, 2004) visando promover comportamentos eco-cidadãos, que nós evocamos aqui, foi realizada em ambiente escolar, junto a alunos de nove e dez anos. Ela foi conduzida em 11 escolas francesas, no âmbito de um programa europeu (ALTENER) e envolveu 700 famílias e 28 professores.

Os principais atos preparatórios que os alunos foram levados a realizar, ao longo de algumas semanas, são em número de quatro. Tratava-se, inicialmente, de efetuar uma observação na escola a fim de anotar "o que estava bem" e "o que não estava bem" em matéria de economia de energia e de proteção do ambiente (primeiro ato preparatório). Em seguida, tratava-se de efetuar uma observação em casa, cada aluno devendo anotar os hábitos familiares que poderiam ser mudados, sem que isto incomodasse alguém (segundo ato preparatório). Tratava-se, ainda, de preencher, com a ajuda dos seus pais (a fim de, evidentemente, comprometê-los também) um longo questionário sobre o tema de economia de energia em casa (terceiro ato preparatório). Enfim, tratava-se de colocar um adesivo em favor da promoção do meio-ambiente sobre a geladeira de casa (quarto ato preparatório).

No final do ano escolar, primeiro cada criança e, em seguida, cada família foram convidadas a se comprometer por escrito a modificar um de seus hábitos (eventualmente dois). Por exemplo, para as crianças: tomar banho de ducha ao invés de banheira; para os pais: não usar o carro para fazer curtos trajetos ou desligar o stand by do televisor. Estes compromissos se concretizaram pela assinatura de dois "contratos": aquele do aluno, que a criança assinava sozinha; e aquele da família, que o aluno e seus pais deveriam assinar conjuntamente. $\mathrm{O}$ ano escolar terminava com uma grande exposição. Este evento tornou-se a ocasião para apresentar às famílias a produção (cartazes, filmes, fotografias, CD-rom ...) realizada pelos alunos, durante o ano escolar, à favor da proteção do meio-ambiente e do controle de energia. Na exposição, um diploma de "Controle da Energia", assinado pelo presidente da Região, pelo Inspetor da Academia e pelo Professor, era entregue às famílias.

O resultado desta ação foi muito positivo. Em proporções muito elevadas (até $100 \%$ em certas classes), alunos e pais dos alunos assumiram o compromisso, por escrito, de realizar atos precisos, susceptíveis de serem traduzidos por uma baixa no consumo de energia. E sabemos que os compromissos assumidos por escrito podem ter efeitos a longo prazo (Girandola \& Roussiau, 2003). Além disso, a dinâmica desencadeada por este procedimento resultou em ações como: a substituição de lâmpadas incandescentes por lâmpadas de baixo consumo em certas escolas; a adoção de coleta seletiva de papéis em outras escolas. Finalmente, os alunos de várias classes tomaram a iniciativa de enviar ao prefeito cartas solicitando, por exemplo, a instalação de "temporizadores" nas lâmpadas dos corredores ou a melhoria da segurança para o acesso dos pedestres à escola e outras tantas ações que permitiram aos alunos exercitar a cidadania e, a partir daí, apropriarem-se dos valores cidadãos desejados.

\section{Promover a eco-cidadania em uma cidade}

A segunda pesquisa-ação (Joule \& Bernard, 2004), visando promover a eco-cidadania foi realizada em uma escala maior, isto é, em uma cidade. Ela foi realizada em uma cidade francesa de importância média (80.000 habitantes). Sobre a base do voluntariado, um grupo de liderança foi constituído por pessoas que deveriam ser "referência" nestas ações de cidadania. Tratava-se de vereadores, responsáveis pelas instituições locais, professores, presidentes de associações, comerciantes e líderes comunitários da cidade em questão. Cada líder tinha a responsabilidade de desencadear uma ação precisa a favor da proteção do meio-ambiente, envolvendo o maior número possível de pessoas, no seu próprio campo de ação (escolas, centros abertos, Casa da Juventude e da Cultura, clubes esportivos, 
associação de inquilinos, associação de proprietários, etc.). Todas estas ações - que são, de fato, atos preparatórios - foram expostas em uma jornada realizada para que cada um soubesse o que os outros tinham feito. Esta jornada, programada para um domingo, possibilitou diversas manifestações (exposições, debates com os políticos locais, etc). Ela foi também e, sobretudo, uma oportunidade para obter compromissos concretos por parte dos habitantes desta cidade que foram convidados a assinar, em família, um "termo de compromisso". Pais e filhos escolhiam o compromisso que desejavam assumir em uma lista de dez itens de compromissos possíveis (por exemplo: substituir uma lâmpada comum por uma lâmpada de baixo consumo, diminuir o aquecedor durante a noite, etc.). Todo "termo de compromisso" assinado era simbolizado por um "sol" que era imediatamente colado sobre uma grande faixa estendida na praça da prefeitura. Uma simples olhada sobre a faixa permitia que cada um acompanhasse a progressão do número de compromissos assumidos ao longo da jornada. Mais de 500 compromissos foram assim assinados durante esta única jornada. Comparando o consumo de energia desta cidade (submetida a uma comunicação de compromisso) com uma cidade controle, na qual apenas os instrumentos clássicos de comunicação foram utilizados - cartazes e cartilhas -, constata-se que o consumo de eletricidade anual médio tinha aumentado menos na cidade onde foi utilizada a comunicação do compromisso $(+6 \%)$ do que na cidade onde foi utilizada uma comunicação clássica (14\%).

\section{Conclusão}

Em seu conjunto, os resultados são encorajadores. Nossas pesquisas, realizadas no âmbito da comunicação do compromisso, mostram, de fato, que se podem otimizar os procedimentos clássicos de comunicação, levando os receptores a realizarem certos atos preparatórios. Também, nossas pesquisas levam a pensar que em matéria de comunicação de massa, bem como em matéria de comunicação de proximidade, a questão a se colocar, quando se buscam efeitos comportamentais, não deve se limitar, como é tradicionalmente o caso, a "quem diz o que a quem?". Ela deve, de preferência, ser: "quem dizo que, a quem, fazendo-o fazer o quê?? (Joule, Py \& Bernad, 2003). Em outros termos, se as boas questões permanecem - Quais são as boas informações a se transmitir? Quais são os melhores argumentos para tal caso particular? - inclui-se aqui uma outra pergunta: qual é ou quais são o(s) bom (bons) ato(s) preparatório(s) a se obter da parte do receptor? É o fato de se levar em conta esta última questão, de forma sistemática, que distingue um procedimento de comunicação do compromisso de um procedimento de comunicação clássica.

Não é, evidentemente, nosso propósito minimizar o interesse e a importância dos numerosos trabalhos realizados no campo da influência social (Mugny, Oberlé \& Beauvois, 1995) ou no campo da persuasão (Bromberg, 1990; Bromberg \& Dubois, 1996), da pragmática (Searle, 1969; Trognon \& Ghiglione, 1993) e, de forma mais geral, no quadro do que podemos chamar de uma psicologia da comunicação (Abric, 1996) ou, ainda, uma psicologia social (cognitiva) da comunicação (Ghiglione, 1997). É preferível militar a favor de uma articulação entre estes trabalhos e os trabalhos sobre o compromisso. Esta articulação nos parece encorajadora como, talvez, uma "primeira chave" de uma nova eficácia em matéria de comunicação de massa e de influência social. Ficam postas, aqui, instigantes perspectivas de pesquisa.

\section{Referências}

Abric, J. C. (1996). La psychologie de la communication. Paris: Colin.

Baluch, B., Randhawa, G., Holmes, S. L. \& Duffy, L. J. (2001). Signing the organ donor card: The relationship between expressed attitude, the actual behavior and personality traits. Journal of Social Psychology, 141, 124-126.

Beauvois, J. L. \& Joule, R. V. (1996). A radical dissonance theory. London \& Bristol: Taylor \& Francis.

Bromberg, M. (1990). La communication: Le pourquoi. Em R. Ghiglione, C. Bonnet \& J. F. Richard (Orgs.), Traité de psychologie cognitive. Vol. 3 (pp. 227-274). Paris: Dunod.

Bromberg, M. \& Dubois, M. (1996). L'étude de la persuasion. Em J. C. Deschamps \& J. L. Beauvois (Orgs.), La psychologie sociale. Vol. 2: Des attitudes aux attributions. Sur la construction sociale de la réalité (pp. 67-90). Grenoble: Presses Universitaires de Grenoble.

Burger, J. M. (1999). The foot-in-the-door compliance procedure: A multiple-process analysis and review. Personality and Social Psychology Review, 3, 303-325.

Deschamps, J. C., Joule, R. V. \& Gumy, C. (2005). La communication engageante au service de la réduction de l'abstentionnisme électoral: une application en milieu universitaire. European Review of Applied Psychology/Revue Européenne de Psychologie Appliquée, 55, 21-27.

Feldman, S. (1966). Cognitive consistency. New York and London: Academic Press.

Freedman, J. L. \& Fraser, S. C. (1966). Compliance without pressure: The foot-in-the-door technique, Journal of Personality and Social Psychology, 4, 195-202.

Ghiglione, R. (1997). La psychologoie sociale cognitive de la communication. Em J. P. Leyens \& J. L. Beauvois (Orgs.), La psychologie sociale. Vol. 3: L'ère de la cognition (pp. 225-251). Grenoble: Presses Universitaires de Grenoble.

Girandola, F. \& Roussiau, N. (2003). L'engagement comme source de modifications à long terme. Les Cahiers Internationaux de Psychologie Sociale, 57, 83-101.

Joule, R. V. (1999). La soumission librement consentie. Em W. Doise, N. Dubois \& J. L. Beauvois (Orgs.), La psychologie sociale. Vol. 4: La construction sociale de la personne (pp. 233-246). Grenoble: Presses Universitaires de Grenoble.

Joule, R.V. (2004). Des intentions aux actes citoyens. Cerveau \& Psycho, 7, 12-17.

Joule, R. V. \& Beauvois, J. L. (2004). La psychologie de l'engagement. Pour la Science, 317(1), 2-5.

Joule, R. V. \& Beauvois, J. L. (1998). La soumission librement consentie. Paris: Presses Universitaires de France.

Joule, R. V. \& Beauvois, J. L. (2002). Petit traité de manipulation à l'usage des honnêtes gens (nouvelle version). Grenoble: Presses Universitaires de Grenoble.

Joule, R. V. \& Bernard, F. (2004). La communication engageante au service de l'éco-citoyenneté: Une recherche-action dans le sud de la France. Em N. De Picolli \& G. P. Quaglino (Orgs.). Psicologia sociale in dialogo. Scritti in onore di Piero Amerio (pp. 265-281). Milano: Unicopli. 
Joule, R. V., Py, J. \& Bernard, F. (2003). Qui dit quoi, à qui, en lui faisant faire quoi? Vers une communication engageante. Em M. Bromberg \& A. Trognon (Orgs.). Psychologie sociale et communication (pp. 205-218). Paris: Dunod.

Kiesler, C. A. (1971). The psychology of commitment. Experiments liking behavior to belief. New York: Academic Press.

Kiesler, C. A. \& Sakumura, J. (1966). A test of a model of commitment. Journal of Personality and Social Psychology, 3, 349-353.

Lewin, K. (1947). Group decision and social change. Em T. M. Newcomb \& E. L. Hartley (Orgs.), Readings in social psychology (pp. 330-344). New York: Henry Holt.

Lewin, K. (1951). Field theory in social science. New York: Harper.

Moriarty, T. (1975). Crime, commitment and the responsive bystander: Two field experiments. Journal of Personality and Social Psychology, 31, 370-376.

Mugny, G., Oberlé, D. \& Beauvois, J. L. (1995). La psychologie sociale. Relations humaines, groupes et influence? Grenoble: Presses Universitaires de Grenoble
Peterson, A. V., Kealey, K. A., Mann, S. L., Marek, P. M. \& Sarason, I. G. (2000). Hutchinson smoking prevention project: Longterm randomized trial in school-based tobacco use prevention: Results on smoking. Journal of National Cancer Institute, 92, 1979-1991.

Searle, J. R. (1969). Speech-acts. An essay in the philosophy of Language. Cambridge: Cambridge University Press.

Trognon, A. \& Ghiglione, R. (1993). Où va la pragmatique? De la pragmatique à la psychologie sociale. Grenoble: Presses Universitaires de Grenoble.

Wicker, A. (1969). Attitude versus actions: The relationship of verbal and over behavior responses to attitude objects. Journal of Social Issues, 25, 41-78.

Recebido em 11.03.2005

Primeira decisão editorial em 29.03.2005

Versão final em 01.04.2005

Aceito em 09.04.2005 